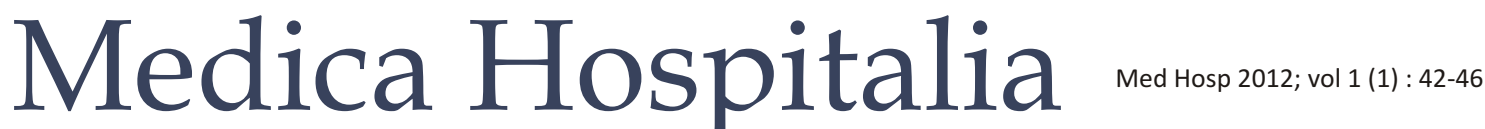

Original Article

\section{Perbedaan Kualitas Hidup Anak dengan Sindrom Nefrotik Resisten Steroid dan Sindrom Nefrotik Relaps}

\author{
Ika Rara Rosita*, M Heru Muryawan** \\ *Mahasiswa FK UNDIP Semarang, **Bagian/SMF IImu Kesehatan Anak Fakultas Kedokteran Universitas Diponegoro/ \\ RSUP Dr.Kariadi Semarang
}

\begin{abstract}
Abstrak
Latar belakang : Penderita sindrom nefrotik resisten steroid (SNRS) dan sindrom nefrotik relaps mempunyai frekuensi lebih banyak untuk menjalani rawat inap dan rawat jalan. Hal tersebut dapat mempengaruhi tingkat kualitas hidup anak. Penelitian tentang kualitas hidup anak SNRS dan SN relaps belum pernah dilakukan. Tujuan penelitian ini adalah untuk membuktikan perbedaan antara kualitas hidup anak SNRS danSN relaps.

Metode : Desain cross sectional pada 35 anak SN (10 SNRSDAN 25 SN relaps) di klinik Anak Rumah Sakit Umum Pusat (RSUP) Dr. Kariadi Semarang dan kunjungan rumah selama April 2011 sampai Juni 2011. Semua subyek dilakukan wawancara terpimpin menggunakan kuesioner PedsQL umum dan spesifik penyakit kronik ginjal.Diagnosis SNRS dan SN relaps secara klinis dan penentuan kualitas hidup menggunakan PedsQL. Penentuan Uji normalitas dianalisis dengan Shapiro-Wilk. Uji beda dianalisis dengan t-test tidak berpasangan.

Hasil : Pada SNRS didapatkan skor umum 55,7 (SD 10,59) dan SN relaps 55,6 (SB 13, 18) ( $p=0,986)$, sedangan pada skor spesifik penyakit kronik ginjal SNRS 53,7 (SD 9,34) dan SN Relaps 58,7 (SD 13,81) ( $p=0,299)$.
\end{abstract}

Simpulan : Tidak terdapat perbedaan secara statistik tentang kualitas hidup anak SNRS danSN relaps.

Kata kunci : kualitas hidup, sindrom nefrotik, PedsQ

\section{The differences between the quality of life in steroid resistant and relapse nephrotic syndrome in children}

\begin{abstract}
Background : Children with steroid resistant nephoitic syndrome (SRNS) and relapse nephrotic syndrome are may often to be hospitalized. It can affect the quality of life of the children. There is no research of quality of life yet in children with SRNS and relapse nephrotic syndrome. The objective of this study is to determine the difference between the quality of life in children with SRNS and relapse nephrotic syndrome.

Methods : Cross-sectional study was conducted on 35 children (25 relapse nephrotic syndrome and 10 SRNS) of out patient in RSUP dr. Kariadi Semarang and home visit during April 2011 to June 2011. The diagnosis of SRNS and relaps NS was clinically and quality of life was assessed by PedsQL. All subjects were interviewed by using General and Specific Chronic Kidney Disease PedsQL Questionnaire. Data Normality was analyzed by Shapirowilk test, comparison tests between SNRS and relaps nephrotic syndrome by independent t-test.

Results : For SRNS group and relaps NS group, the general PedsQL score was 55,7 (SD 10,59) and 55,6 (SD 13,18) $(p=0,986)$, while the specific chronic kidney disease PedsQLwas 53,7 (SD 9,34) and 58,7 $(\mathrm{SD} 13,81)(p=0.299)$, respectively.

Conclusion : There was no significant difference of the quality of life between children with SRNS and relapse NS.
\end{abstract}

Keywords : quality of life, nephrotic syndrome, PedsQL

\section{PENDAHULUAN}

Sindrom nefrotik (SN) merupakan kumpulan gejala yang ditandai dengan proteinuria masif, hipoalbuminemia berat, edema dengan atau tanpa hiperkolesterolemia. Klasifikasi SN berdasar respon pengobatan steroid meliputi Sindrom Nefrotik Sensitif Steroid (SNSS) dan Sindrom Nefrotik Resisten Steroid (SNRS). ${ }^{2}$
Angka kejadian SN di Indonesia 6 kasus pada tiap 100.000 anak pertahun. Perbandingan laki-laki dan perempuan 2:1. ${ }^{3}$ Dari angka kejadian tersebut menurut International Study of Kidney Disease in Children (ISKDC), pada pengobatan inisial terjadi remisi total $94 \%$. Sebagian besar SNSS akan mengalami relaps (60-70\%) dan 50\% diantaranya mengalami relaps sering. Sekitar 10-20\% tidak respon terhadap terapi kortikosteroid, yang kemudian diklasifikasikan dalam SNRS. ${ }^{4}$ 
Penilaian kualitas hidup (Quality of Life, QoL) merupakan suatu konsep yang mencakup karakteristik fisik dan psikologis secara luas yang menggambarkan kemampuan individu berperan dalam lingkungannya dan memperoleh kepuasan dari yang dilakukannya. Penilaian QoL dipengaruhi oleh keadaan fisik, mental, sosial, dan emosional. ${ }^{5}$ Penilaian tersebut dapat dilakukan dengan instrumen pengukur kualitas hidup Pediatric Quality of Life Inventory (PedsQL). ${ }^{6}$

Penilaian kualitas hidup sangat penting pada SNRS dan SN relaps karena mempunyai frekuensi lebih banyak untuk menjalani rawat inap maupun sering kontrol rawat jalan. Pada anak sekolah akan mempengaruhi beberapa hal seperti gangguan pada pertumbuhan fisiknya, terjadinya hambatan perkembangan (keterampilan gerak motorik dan ancaman perubahan terhadap perkembangan identitas seksual serta peran sesuai gender), terjadinya gangguan kognitif (pelupa, hambatan berpikir, tidak mampu berkonsentrasi, dan ketakutan), anak menjadi sering membolos, terjadi gangguan perkembangan emosional, serta gangguan pada hubungan sosialnya. ${ }^{7}$

Penelitian tentang kualitas hidup anak yang menderita SNRS dan SN relaps belum pernah dilaporkan. Tujuan penelitian ini adalah untuk mengetahui perbedaan kualitas hidup anak dengan SNRS dan SN relaps. Manfaat penelitian ini untuk menambah informasi tentang kualitas hidup anak dengan SNRS dan SN relaps dan diharapkan dapat meningkatkan pelayanan dan mencegah efek hospitalisasi pada penderita tersebut.

\section{METODE}

Penelitian cross-sectional pada orangtua dari anak yang menderita sindrom nefrotik dengan kriteria resisten steroid dan relaps. Jumlah subyek yang dibutuhkan adalah 35 anak. Pemilihan subyek menggunakan consecutive sampling. Penelitian dilakukan di klinik Anak RSUP Dr. Kariadi Semarang dan kunjungan rumah dari April 2011 sampai Juni 2011.

Diagnosis SNRS dilakukan secara klinis yaitu, belum tercapai remisi setelah pengobatan prednisone dosis penuh selama 28 hari, sedangkan dikatakan SN relaps bila terjadi proteinuria $\geq$ positif 2 setelah sembuh. Penentuan kualitas hidup menggunakan Pediatric Quality of Life Inventory (PedsQL) ${ }^{6}$, terdiri dari skor umum meliputi fisik,emosi, sosial, sekolah dan mental dan skor spesifik penyakit kronik ginjal (tabel3).

Kriteria inklusi adalah orangtua dari anak SN yang berumur 5-12 tahun dan anak sudah bersekolah, sedangkan jika orang tua dari anak tersebut tidak kooperatif, tidak komunikatif, dan anak menderita keterbelakangan mental maka subyek dieksklusi.

Subyek yang telah bersedia mengikuti penelitian dilakukan pemeriksaan Pengukuran kualitas hidup dengan menggunakan kuesioner PedsQL umum dan PedsQL spesifik penyakit kronik ginjal. Analisis data dengan uji t-test tidak berpasangan.

\section{HASIL}

Sebanyak 35 anak penderita SN terdiri dari 25 $(71,4 \%)$ SN relaps dan $10(28,6 \%)$ SNRS. Rerata umur 9,20 $\pm 2,08$. Jenis kelamin laki-laki 21 orang dan wanita 14 orang. Karakteristik umum subyek penelitian ditunjukkan pada tabel1.

Sembilan puluh satu persen subyek telah menderita SN lebih dari 6 bulan, 17,1\% mengalami komplikasi dan $20 \%$ dengan penyakit lain. Karakteristik umum subyek yang berhubungan dengan kesehatan ditunjukkan pada tabel 2 .

Penderita SNRS maupun SN relaps mempunyai nilai total PedsQL $\leq 65,48$, yaitu kualitas at risk atau di bawah kualitas hidup normal. Skor umum dan skor spesifik penyakit ginjal pada penelitian ini adalah (tabel3).

Kualitas hidup dengan skor umum $(p=0,986)$ maupun skor khusus $(p=0,299)$ tidak didapatkan perbedaan bermakna secara statistik antara SNRS dan SN relaps.

\section{PEMBAHASAN}

Penelitian kualitas hidup anak dengan sindrom nefrotik (SN) dilakukan berdasarkan kenyataan bahwa SN merupakan suatu penyakit kronis yang diobati dengan pengobatan kortikosteroid jangka panjang dan frekuensi kambuh yang sering sehingga dapat menyebabkan gangguan pada perilaku umum dibandingkan dengan anak-anak yang sehat pada usia yang sama. Pasien dengan $\mathrm{SN}$ dapat terjadi stress nonspesifik terhadap anak yang sedang berkembang dan keluarganya. Perkembangan dunia sosial anak menjadi terbatas. ${ }^{8,9}$

Rerata umur subyek penelitian adalah 9,20 $\pm 2,08$ tahun dengan rentang usia 8-12 tahun. Sesuai penelitian Damanik di Jogjakarta tahun 2006 yang melaporkan penderita SN paling sering berusia 8-15 tahun. ${ }^{10}$ Sejak anak memasuki usia sekolah, intelektual, sosial, dan perkembangan emosi merupakan faktor yang mempengaruhi persepsi seorang anak terhadap kualitas hidupnya, rentang usia 5-13 tahun berada dalam periode perkembangan sosial. ${ }^{11}$

Pendidikan orang tua pada penelitian ini sebagian besar adalah sekolah dasar, pekerjaan ayah sebagian besar adalah karyawan swasta dan kebanyakan ibu tidak bekerja serta pendapatan keluarga sebagian besar $\leq \mathrm{Rp}$ 600.000,-Pendidikan dan pekerjaan mempengaruhi ketaatan berobat dan kontrol ke fasilitas medis yang ada. Keluarga dengan penghasilan rendah biasanya akan cenderung untuk mengabaikan kebutuhan anak. Keadaan tersebut mempengaruhi kualitas hidup anak. 


\begin{tabular}{|c|c|c|c|}
\hline Variabel & $\mathbf{N}$ & Variabel & $\mathbf{N}$ \\
\hline Tingkat Pendidikan Ayah & & Pendapatan Keluarga Total & \\
\hline Tidak bersekolah & 1 & $=$ Rp. $600.000,-$ & 25 \\
\hline SD & 12 & Rp. 600.000,-- Rp. 1.200.000,- & 7 \\
\hline SMP & 8 & $=$ Rp. 1.200.000,- & 3 \\
\hline SMA & 10 & & \\
\hline PT & 4 & & \\
\hline Tingkat Pendidikan Ibu & & Jumlah Anak & \\
\hline Tidak bersekolah & 1 & $=3$ & 23 \\
\hline SD & 12 & $4-6$ & 8 \\
\hline SMP & 9 & $>6$ & 4 \\
\hline SMA & 11 & & \\
\hline PT & 2 & & \\
\hline Pekerjaan Ayah & & Urutan Anak & \\
\hline Tidak bekerja & 1 & 1 & 17 \\
\hline Tukang/buruh & 14 & 2 & 8 \\
\hline PNS/ABRI & 2 & 3 & 2 \\
\hline Karyawan Swasta & 15 & 4 & 1 \\
\hline \multirow[t]{2}{*}{ Lain-lain } & 3 & 5 & 4 \\
\hline & & 6 & 3 \\
\hline \multicolumn{4}{|l|}{ Pekerjaan Ibu } \\
\hline Tidak bekerja & 14 & & \\
\hline Tukang/buruh & 7 & & \\
\hline PNS/ABRI & 1 & & \\
\hline Karyawan Swasta & 8 & & \\
\hline Lain-lain & 5 & & \\
\hline
\end{tabular}

\section{TABEL 2 \\ Karakteristik subyek berhubungan dengan kesehatannya}

\begin{tabular}{|cc|}
\hline Karakteristik & n \\
\hline Lama subyek menderita SN & 3 \\
= 6 bulan & 32 \\
$>6$ bulan & \\
Komplikasi lain & 6 \\
Ada & 29 \\
Tidak & \\
Penyakit lain & 7 \\
Ada & 28 \\
Tidak &
\end{tabular}

Hasil penelitian ini mendapatkan lama sakit sebagian besar $>6$ bulan.Semakin lama terapi yang harus dijalani maka semakin buruk kualitas hidup anak dengan sindrom nefrotik. Anak yang menjalani terapi $>6$ bulan berarti respon terapi jelek atau lebih ke arah resisten steroid sedangkan $\mathrm{SN}$ resisten steroid seringnya relaps dan tidak responsif terhadap terapi. Kualitas hidup anak menjadi normal bila edukasi dan ketaatan berobat dijalani dengan baik walaupun harus menjalani pengobatan jangka panjang. ${ }^{8}$

Hasil penelitian didapatkan keluarga penderita SN sebagian besar dengan jumlah anak $\leq 3$ dan nomor urut anak pertama. Jumlah anak dan nomor urut anak tersebut berhubungan dengan pengasuhan. Menurut Satoto, semakin kecil jumlah anak atau nomor urut anak dalam keluarga, maka waktu yang tersedia untuk mendapatkan informasi kesehatan dan konsultasi ke dokter akan makin besar, karena beban kerja lebih sedikit dibandingkan jumlah anak yang banyak. Sebaliknya makin besar jumlah anak maka kesempatan mendapatkan penyuluhan atau konsultasi dengan dokter mungkin cukup, namun waktu yang tersedia lebih terbatas karena kesibukan mengurus anak. ${ }^{12}$

Nilai total PedsQL menyatakan nilai kualitas hidup anak.Rerata nilai total PedsQL pada populasi anak sehat adalah $81,38 \pm 15,90$. Sehingga dinyatakan kualitas hidup "normal" jika nilai total Peds $Q L \geq 65,48$ ( $\geq-1$ SD) dan kualitas hidup "at risk" jika nilai total PedsQL $<65,48 .{ }^{13}$ Dalam penelitian ini didapatkan rerata nilai kualitas 


\section{TABEL 8}

Rerata dan standar deviasi kualitas hidup subyek dengan skor umum dan skor spesifik penyakit ginjal pada SN relaps dan SNRS

\begin{tabular}{|c|c|c|c|}
\hline Skor & SN relaps & SN relaps & $\boldsymbol{p}$ \\
\hline Umum & $55,6(S D 13,18)$ & 55,7 (SD 10,59) & 0,986 \\
\hline Fisik & 60,63 (SD 20,69) & 51,57 (SD 21,86) & 0,693 \\
\hline Emosi & 63,2 (SD 25,61) & 64 (SD 23,78) & 0,933 \\
\hline Sosial & 76,67 (SD 21,21) & 80,35 (SD 8,23) & $0,0,79$ \\
\hline Sekolah & $65(S D 27,18)$ & $63(S D$ 17,19) & 0,384 \\
\hline Mental & $12,5(S D 18,30)$ & 19,58 (SD 14,7) & 0,790 \\
\hline Spesifik Penyakit Kronik Ginjal & 58,7 (SD 13,81) & 53,7 (SD 9,34) & 0,299 \\
\hline Fisik (general fatigue) & 47,25 (SD 24,48) & 59,38 (SD 29,05) & 0,218 \\
\hline Penyakit (kidney disease) & $53,2(S D 20,30)$ & 50 (SD 18,57) & 0,968 \\
\hline Terapi (treatment problem) & 75,26 (SD 15,49) & 44,5 (SD 10,39) & 0,289 \\
\hline Sosial (family and pier interaction) & 54,33 (SD 19,56) & 60,42 (SD 17,77) & 0,117 \\
\hline Kekawatiran (worry) & $53,2(S D 26,38)$ & 56,5 (SD 19,59) & 0,723 \\
\hline Penampilan (perceived physical appearance) & 63,33 (SD 19,05) & 50 (SD 35,09) & 0,072 \\
\hline Komunikasi (communication) & 64,43 (SD 37,36) & 55 (SD 40,57) & 0,078 \\
\hline
\end{tabular}

Keterangan : Rerata nilai total PedsQL populasi anak sehat adalah 81,38 $\pm 15,90$ Kualitas hidup "normal" jika nilai total PedsQL $\geq 65,48$ ( $\geq-1$ SD) Kualitas hidup "at risk" jika nilai total PedsQL $<65,48$.

hidup anak dengan SNRS dan SN relaps di bawah nilai populasi anak sehat.

Penelitian Ruth 2004, didapatkan kesulitan atau gangguan dalam interaksi sosial,yang membawa pengaruh pada kondisi mental maupun psikososialanak, orang tua, dan perawat anak termasuk guru bila anak telah memasuki usia sekolah. ${ }^{14}$ Hal tersebut sejalalan dengan penelitian ini karena pada jenis $\mathrm{SN}$ sensitif steroid juga mengalami suatu proses kekambuhan yang akan menyebabkan memburuknya perilaku.

Pada penelitian ini ditemukan bahwa terjadi penurunan kualitas hidup dibandingkan pada waktu anak tersebut sehat. Sesuai dengan penelitian Neuhaus TJ dkk, yang menyatakan bahwa pada anak SN biasanya menunjukkan perilaku yang abnormal saat berada dalam keadaan kekambuhan yang merupakan pengaruh pengobatan prednison. ${ }^{15}$

Hasil penelitian ini secara statistik didapatkan kualitas hidup anak tidak berbeda bermakna antara SN relaps dengan anak SNRS, namun terdapat perbedaan rerata nilai kualitas hidup antara jenis $\mathrm{SN}$ relaps dan SNRS. Pada skor PedsQL umum, SNRS mempunyai nilai rerata sebesar 0,08 poin lebih tinggi dibandingkan SN relaps sedangkan untuk skor PedsQL spesifik pada kelompok SN relaps mempunyai nilai rerata sebesar 5,03 poin lebih tinggi dibandingkanjenis SNRS.

Perbedaan kategori skor umum total untuk seluruh item pada tabel ini memiliki kelemahan yaitu tidak dapat menggambarkan fungsi-fungsi khusus yang mungkin terganggu dan yang tidak terganggu pada penderita SN. Namun baik untuk melihat kualitas hidup secara umum. Untuk dapat mengetahui hal spesifik terganggu pada anak dengan sindrom nefrotik, juga dilakukan penelitian menggunakan skor spesifik untuk penyakit kronik ginjal. Pada penelitian tersebut digunakan untuk membandingkan skor kualitas hidupnya dengan hasil dari skor umum.

Keterbatasan penelitian ini adalah tidak dibedakan antara SN relaps jarang dan sering. Penilaian PedsQL tidak dilakukan pada setiap relaps dan pengisian kuesioner diwakili orang tua (parent proxy) yang kemungkinan hasil akan berbeda apabila pengisian kuesioner dinilai berdasar persepsi sendiri (self report) oleh penderita SN karena perjalanan hidup anak dengan penyakit kronis ini tidak dirasakan sepenuhnya oleh anak, sehingga anak menilai bahwa kualitas hidupnya baik-baik saja atau anak persepsinya lebih optimis.

\section{SIMPULAN}

Tidak terdapat perbedaan secara statistik bermakna kualitas hidup anak antara $S N$ relaps dan SNRS.Walaupun antara SNRS dan SN relaps sering tidak berbeda bermakna, namun keduanya mempunyai nilai $P e d s Q l$ di bawah normal, sehingga penelitian intervensi untuk meningkatkan kualitas hidup anak sindrom nefrotik perlu dilakukan. 


\section{DAFTAR PUSTAKA}

1. Niaudet $P$. Boyer O. Idiopathic nephritic syndrome in children: clinical aspects.Dalam: Avner ED, Harmon WE, Niaudet P, Yashikawa N, penyunting. Pediatric Nephrology. Edisi ke-6. Berlin Hiedelberg: Springer-Verlag, 2009; 667-702.

2. Haycock G. The child with idiopathic nephritic syndrome. Dalam : Webb N, Postlethwaite R,,penyunting. Clinical pediatric nephrology. Edisi ke-3.Oxford: Oxford University Press, 2003; 341-66.

3. Wila Wirya IGN. Penelitian beberapa aspek klinis dan patologi anatomis sindrom nefrotik primer pada anak di Indonesia (Disertasi).Jakarta:FKUI; 1992.

4. International study of kidney disease in children. Nephrotic syndrome in children. Prediction of histopathology from clinical and laboratory characteristic at time of diagnosis. Kidney Int.1978;13:159

5. Varni JW, Limbers CA, Burwinkle TM. Impaired health-related quality of life in children and adolescents with chronic conditions: a comparative analysis of 10 disease clusters and 33 disease categories/severities utilizing the PedsQL ${ }^{\text {TM }} 4.0$ Generic Core Scales [serial online]. 16 Juli 2007 [cited 11 Oktober 2010].from : http://www.hqlo.com/ content/5/1/143

6. Varni JW. The PedsQLTM measurement model for the pediatric quality of life inventory.[serial online]. 2010 [cited 29 November 2010]. from : http://www.pedsql.org/ pedsql2.html

7. Sri IE. Hubungan antara stress hospitalisasi dengan perubahan pola tidur anak usia prasekolah yang dirawat di ruang cempaka BRSD RAA Soewondo Pati [skripsi]. Semarang: Program Ilmu Keperawatan Fakultas Ilmu Keperawatan dan Kesehatan Universitas Muhammadiyah Semarang; 2008. http://digilib.unimus.ac.id/files/disk1/104/jtptunimus-gdlsriindahek-5180-3-babii.pdf

8. Simatupang DF.Tingkat kualitas hidup anak dengan sindrom nefrotik primer kelainan minimal dan bukan kelainan minimal di RSUP Dr. Sardjito Yogyakarta (Tesis). Yogyakarta: Program Pasca Sarjana Universitas Gajah Mada; 2009.

9. Mehta M, Bangga A, Pande P, Bajaj G, Srivastava RV.Behaviour problems in nephrotic syndrome.Indian Peiatr. 1995 ;32:1281-6

10. Damanik MP. Hubungan antara human leucocyte antigens (HLA) dengan SN primer pada anak di RSUP Dr. Sardjito Yogyakarta.(Disertasi) Yogjakarta : Medica Fakultas kedokteran Universitas Gajah Mada Yogyakarta.2006

11. Levine MD. Middle childhood. Dalam: Levine MD, Carey WB, Crokcker AC, penyunting.Development behavior pediatrics. Edisi ke-3. Philadelphia: WB Saunders Co. 1999:51-68.

12. Satoto, Pertumbuhan dan Perkembangan Anak, (Disertasi), Semarang:Undip, 1990.

13. Health Assessment ProjectFirst Year Results, Data Insights Report No. 10 (Sacramento: Children's Health Assessment Project, November 2002), available online at http://www.mrmib.ca.gov/MRMIB/HFP/PedsQLYr2CHH S.pdf.

14. Ruth EM, Landolt MA, Neuhaus TJ, Kemper MJ. Health Related quality of life and psychosocial adjustment in steroid sensitive nephrotic syndrome.J Pediatr,2004;145:778-83.

15. Neuhaus TJ, Langlois V, Licht C. Behavioural abnormalities in children with nephritic syndrome-an underappreciated complivation of a standart treatment? Nephrol Dial Transplant.2010;25:2397-9. 